\title{
Investigation of a New Atomization Process using Liquid Carbon Dioxide
}

\author{
Clara Lauscher*, Gerhard Schaldach, Markus Thommes \\ Laboratory of Solids Process Engineering - TU Dortmund University, Dortmund, Germany \\ *Corresponding author: clara.lauscher@tu-dortmund.de
}

\begin{abstract}
A new atomization process for producing droplets in the low micrometre size range is presented. The approach is based on an emulsification process of liquid $\mathrm{CO}_{2}$ with a non-miscible liquid and a subsequent expansion of the high-pressure emulsion to form an aerosol with small droplets. First investigations were conducted using deionized water as disperse phase. For the emulsification process, the water was injected into the liquid $\mathrm{CO}_{2}$ through an orifice. Subsequently, the formed high-pressure emulsion was expanded through a second nozzle. Different combinations of emulsification and expansion nozzles were utilized to investigate their impact on the droplet size in the emulsion and in the aerosol, respectively. Median droplet diameters in the aerosol down to $3 \mu \mathrm{m}$ were achieved for low water mass loads.
\end{abstract}

\section{Keywords}

atomization, droplets, emulsification, liquid carbon dioxide

\section{Introduction}

The field of application for small particles is wide. For example, in chemical industry, the high specific surface can be beneficial for catalysis [1]. In addition, in pharmaceutical applications, the high specific surface can improve the dissolution rates of poorly water soluble active pharmaceutical ingredients [2]. A commonly used process to produce small particles is spray drying. Unfortunately, conventional atomizers show limitations regarding the production of droplets in a low micrometre size range. Therefore, a new approach to produce droplets in this size range is investigated.

The new idea is based on a transfer of a one-step atomization process into a two-step process comprising an emulsification process followed by the atomization process (figure 1). The aim is to emulsify a solution (phase 1) in liquid $\mathrm{CO}_{2}$ to form a high-pressure emulsion with small droplets. Afterwards, the emulsion is expanded through an expansion nozzle with a small length to diameter ratio leading to a rapid pressure drop. The $\mathrm{CO}_{2}$ evaporates as soon as the pressure drops below the saturation vapour pressure and an aerosol of the solution and gaseous $\mathrm{CO}_{2}$ is produced. Afterwards, the droplets of the solution can be dried, resulting in small particles.

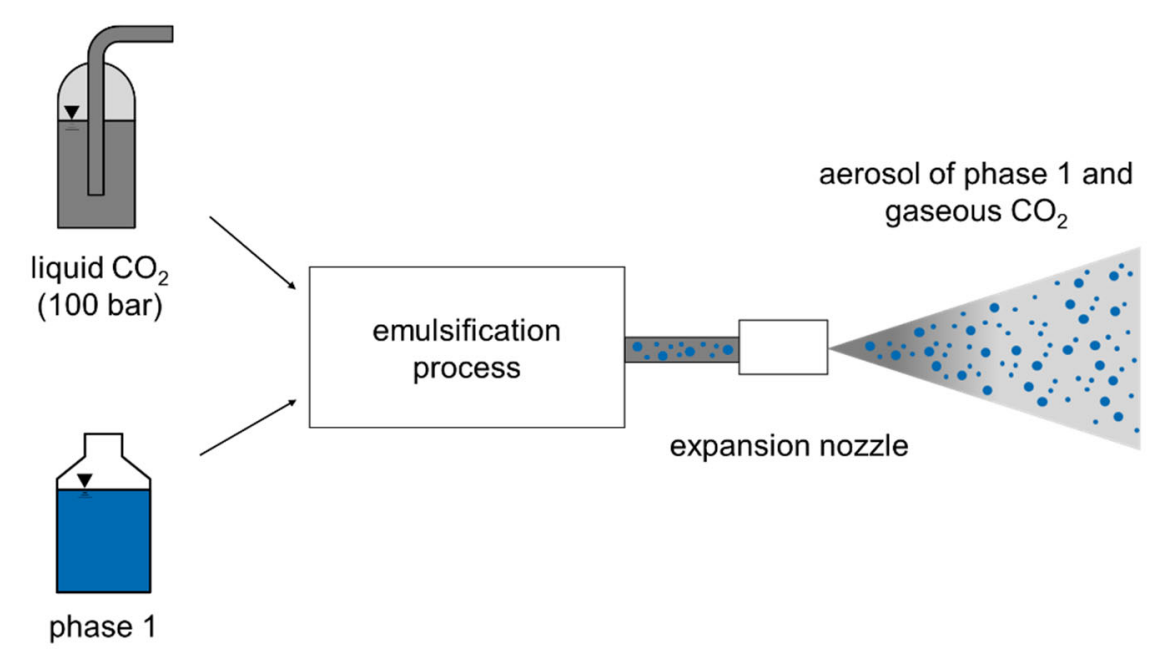

Figure 1. Two-step process: emulsification process followed by an expansion process. 
The advantage of an emulsification process in comparison to an atomization process in gas is presented in [3]. Water was jetted into gaseous $\mathrm{CO}_{2}$ at atmospheric pressure. The modes of disintegration Rayleigh breakup, sinuous wave breakup, and atomization were identified and their boundaries were marked in the Ohnesorge diagram with solid lines (figure 2). In comparison, $\mathrm{CO}_{2}$ was pressurized and water was thus jetted into liquid / supercritical $\mathrm{CO}_{2}$ (dotted lines). It was concluded that the higher densities of liquid and supercritical $\mathrm{CO}_{2}$ led to a higher mode of disintegration under otherwise similar conditions, which usually leads to smaller droplets.

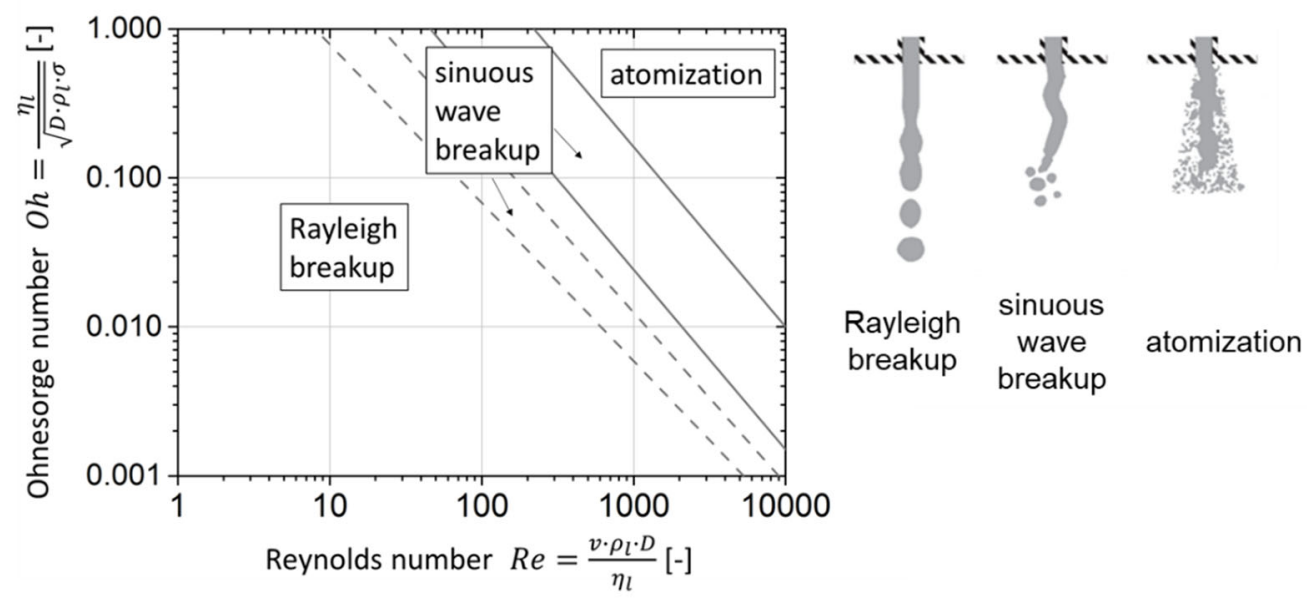

Figure 2. Classification of modes of disintegration, solid lines: atmospheric pressure, dotted lines: elevated gas pressure; modified from $[3,5]$.

For clarification of the process conditions and differentiation from other processes, the operating field is shown in a phase diagram of $\mathrm{CO}_{2}$ (figure 3 ). The process conditions were set to work with liquid $\mathrm{CO}_{2}$ at a pressure of about 100 bar (grey rectangle).

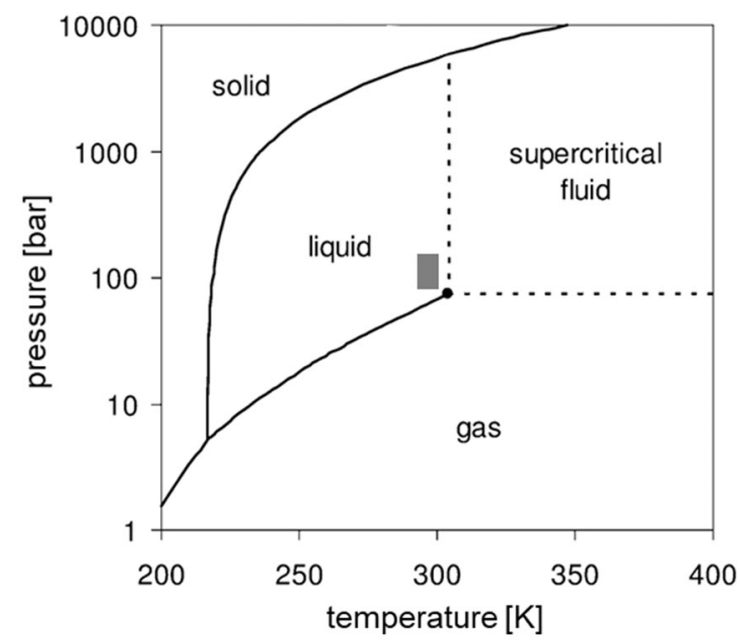

Figure 3. Operating field in the phase diagram of $\mathrm{CO}_{2}$, modified from [6]. 


\section{Materials and Methods}

The aerosol generation was studied using pure solvents, thus removing possible confounding variables. In this investigation, deionized water was selected as the disperse phase. The experimental set-up, developed for these investigations, is shown in figure 4. Liquid $\mathrm{CO}_{2}\left(\mathrm{CO}_{2} 4.5\right.$, Messer Industriegase, Bad Soden, Germany) was provided in a riser pipe bottle with two valves. To enable the targeted operating field of about 100 bar, the liquid $\mathrm{CO}_{2}$ was additionally pressurized using $\mathrm{N}_{2}$ (technical $\mathrm{N}_{2}$, Messer Industriegase, Bad Soden, Germany). Water was injected into the mixing chamber through an emulsification nozzle using an HPLC pump (80 P, Knauer, Berlin, Germany). Afterwards, the highpressure emulsion was expanded through an expansion nozzle with a low length to diameter ratio $\left(\mathrm{L} / \mathrm{D}^{\circ} \approx 1.3\right)$ in which the pressure dropped rapidly, and the liquid $\mathrm{CO}_{2}$ evaporated. The emulsification nozzle diameters ( $D_{1}: 100$ and $200 \mu \mathrm{m}$ ) were varied to investigate their impact on the final droplet size of the aerosol. Different mass flow rates of water $\left(\dot{\mathrm{m}}_{\mathrm{W}}\right)$ between $1 \mathrm{~g} / \mathrm{min}$ and $20 \mathrm{~g} / \mathrm{min}$ were utilized to generate mass fractions $(\mu)$ between 0.01 and 0.09 of water in liquid $\mathrm{CO}_{2}$. Two expansion nozzles $\left(\mathrm{D}_{2}\right.$ : 200 and $300 \mu \mathrm{m}$ ) were used to study different total flow rates $(140 \mathrm{~g} / \mathrm{min}$ and $260 \mathrm{~g} / \mathrm{min})$. The mass flow rate of the liquid $\mathrm{CO}_{2}\left(\dot{\mathrm{m}}_{\mathrm{CO}_{2}}\right)$ was determined with a Coriolis flow meter (mini CORI-FLOW, Bronkhorst, Kamen, Germany).

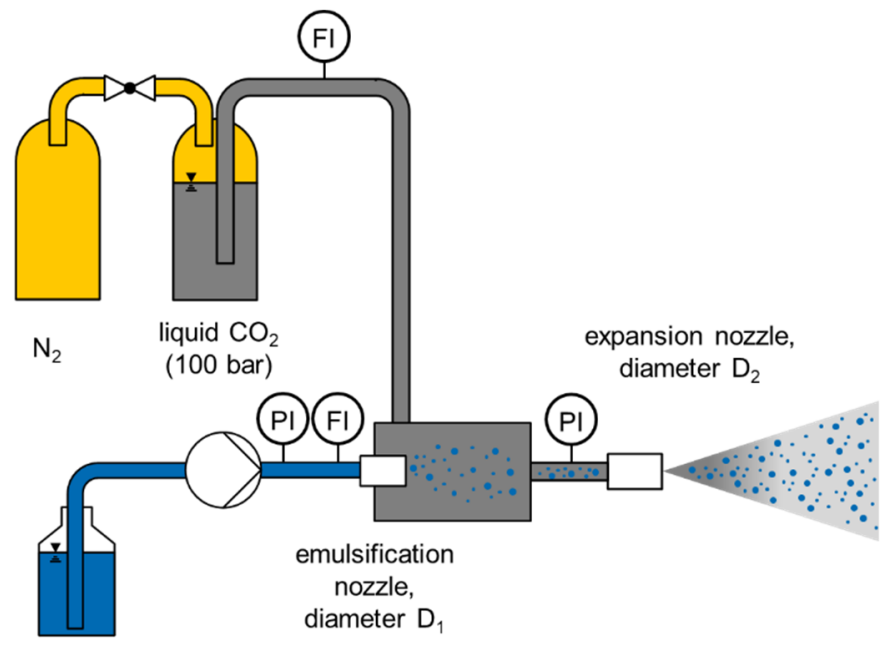

Figure 4. Experimental set-up.

The droplet size measurements in the emulsion were enabled by the installation of a high-pressure cuvette between the mixing chamber and the expansion nozzle. Images of the emulsion were taken with a digital camera (Nikon Z6, Sendai Nikon Corporation, Sendai, Japan) (figure 5) and subsequently analysed regarding the droplet diameter using the software Image [7]. The droplet size in the aerosol was analysed using laser diffraction (Spraytec, Malvern Instruments, Malvern, United Kingdom) at a distance of $350 \mathrm{~mm}$ to the expansion nozzle. The detector range was adjusted to prevent distortion of the droplet size measurement by the $\mathrm{CO}_{2}[8]$. 


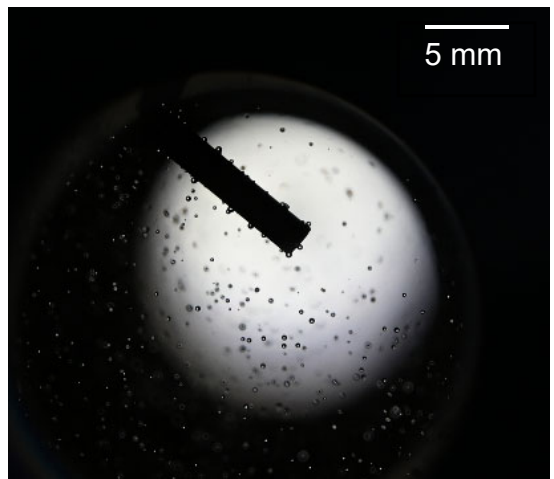

Figure 5: Image of the emulsion for an emulsification nozzle diameter of $100 \mu \mathrm{m}$, an expansion nozzle diameter of $300 \mu \mathrm{m}$ and a water mass load of 0.01 .

\section{Results and Discussion}

The results of the droplet size measurements in the emulsion are shown in figure 6 . The dimensionless droplet diameters as a function of the Reynolds number are shown for the $200 \mu \mathrm{m}$ expansion nozzle in the left diagram and for the $300 \mu \mathrm{m}$ expansion nozzle in the right diagram. The average dimensionless droplet diameters are all in a similar range between 2 and 6.5. For the $200 \mu \mathrm{m}$ expansion nozzle, higher values were measured than for the larger expansion nozzle, especially for small Reynolds numbers. This might be explained by coalescence. For the $200 \mu \mathrm{m}$ expansion nozzle, a smaller flow rate of $\mathrm{CO}_{2}$ was measured, leading to a higher water mass load and residence time at a constant Reynolds number. Therefore, a higher probability for coalescence of the small droplets could be assumed.
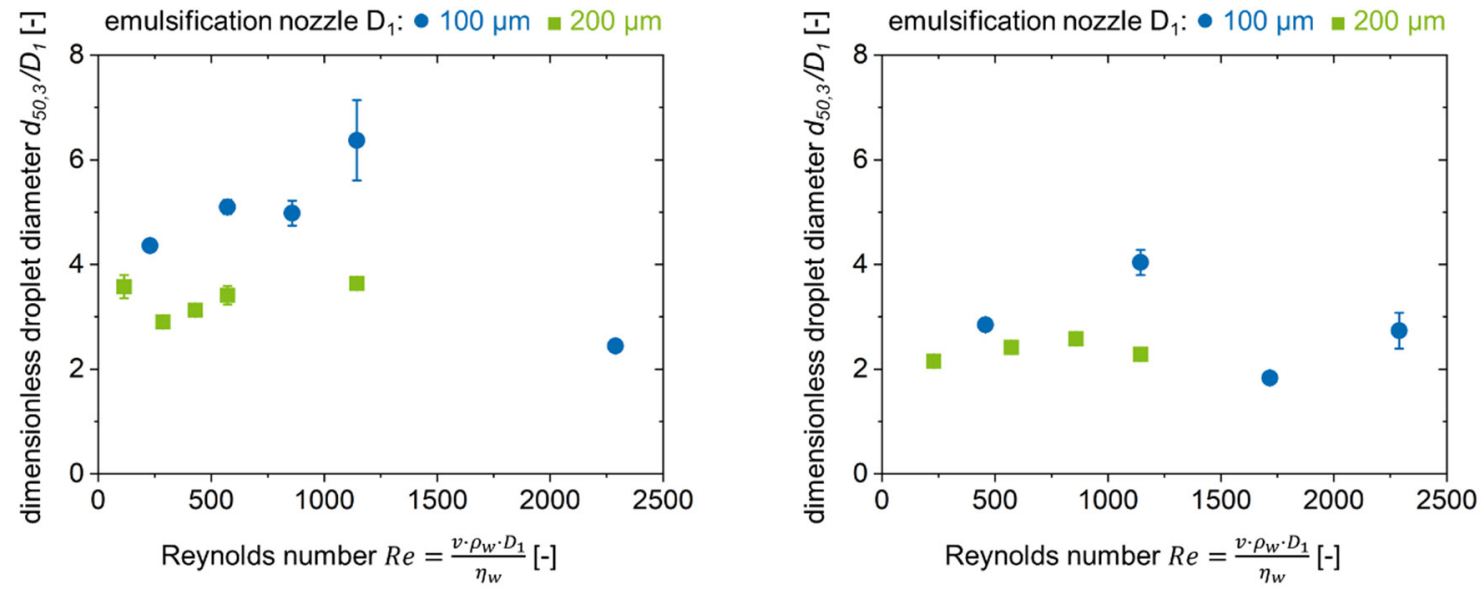

Figure 6. Droplet diameter in the emulsion in dependence of the water mass load for an expansion nozzle diameter of $200 \mu \mathrm{m}$ (left) and for an expansion nozzle diameter of $300 \mu \mathrm{m}$ (right) (av $\pm \mathrm{Sm} ; \mathrm{n}=3)$.

For comparison with literature data, operating points for the $300 \mu \mathrm{m}$ expansion nozzle are marked in figure 7. Operating points in all three regimes of disintegration were investigated. According to literature, the dimensionless droplet diameter should have a value of about 1.9 for the operating point in the Rayleigh breakup regime [9]. The measured value for the $300 \mu \mathrm{m}$ expansion nozzle is slightly higher at about 2.1 and thus in good accordance with the expected value. A strong decrease in droplet size through a change in mode of disintegration could not be observed. 


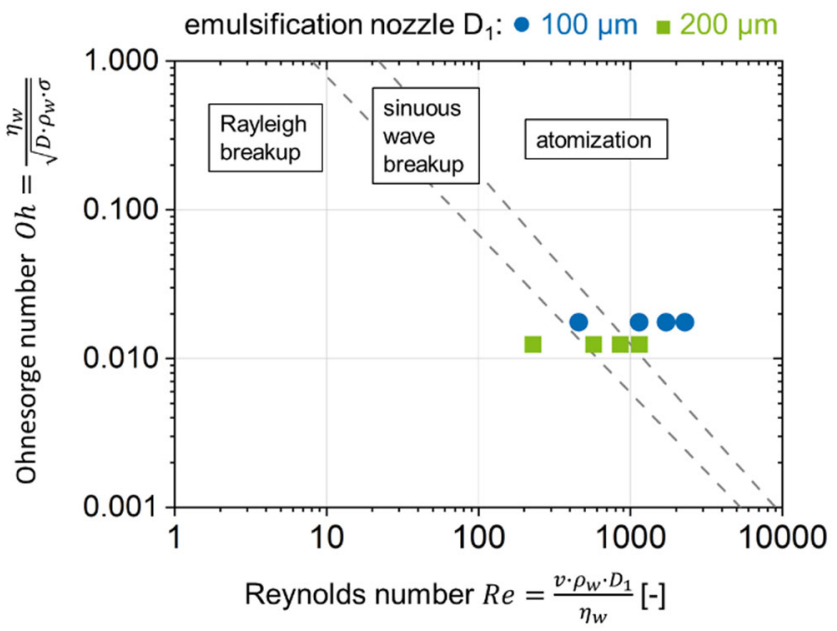

Figure 7. Ohnesorge diagram with disintegration regimes and marked operating points for an expansion nozzle of $300 \mu \mathrm{m}$.

Figure 8 shows the median droplet diameter in the aerosol in dependence of the water mass load for the expansion nozzle with an opening of $200 \mu \mathrm{m}$ (left) as well as corresponding results for the $300 \mu \mathrm{m}$ expansion nozzle (right). For both expansion nozzles, the median droplet diameter increases with increasing water mass load. A significant influence of the emulsification nozzle could not be identified. The expansion nozzle with a diameter of $200 \mu \mathrm{m}$ in combination with the smaller emulsification nozzle led to smaller droplet diameters in the final aerosol, which might be caused by smaller droplets in the emulsion. In contrast, no influence of the different applied emulsification nozzles was observed for the $300 \mu \mathrm{m}$ expansion nozzle. This suggests that the emulsification process only has a minor influence on the resulting droplet size in the aerosol under the investigated process conditions and that the droplet size in the aerosol is more likely determined by the water mass load. By definition, the mass flow rate of $\mathrm{CO}_{2}$ normalized to the water mass flow rate decreases with increasing water mass load, so that a larger median droplet size at higher water mass loads might be caused by the reduction of the relative amount of evaporating $\mathrm{CO}_{2}$.
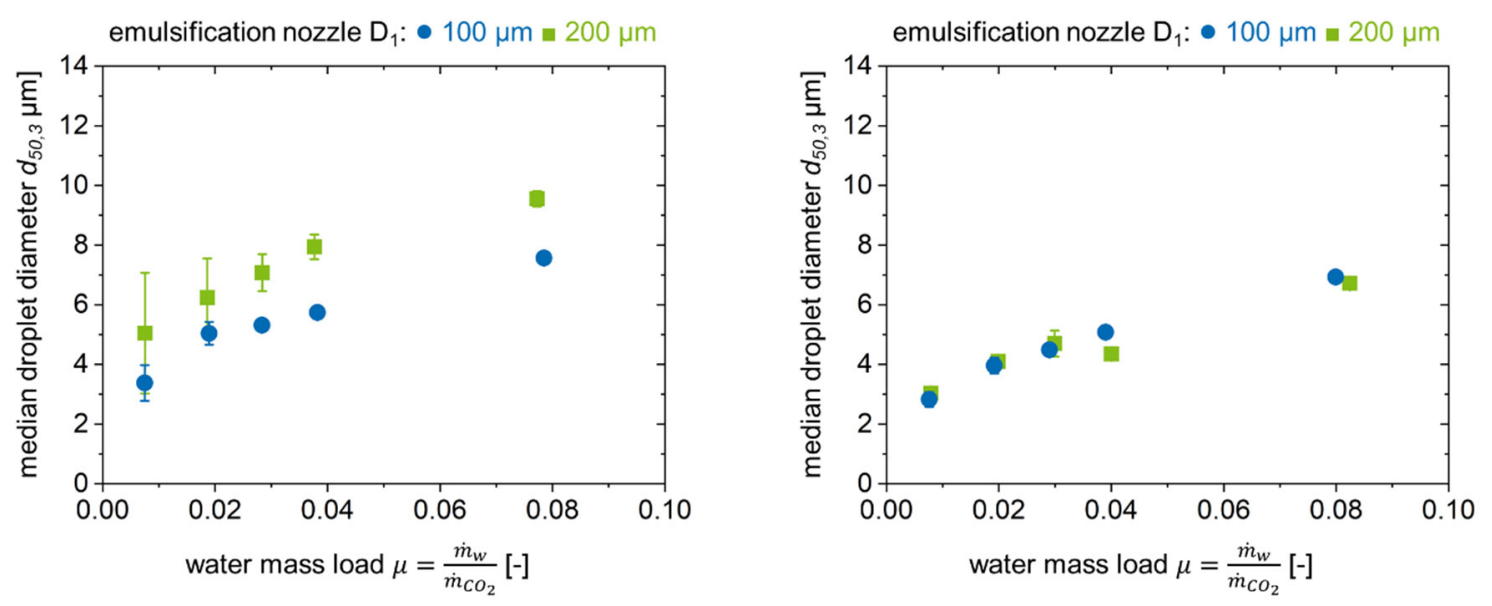

Figure 8. Droplet diameter in the aerosol in dependence of the water mass load for an expansion nozzle diameter of $200 \mu \mathrm{m}$ (left) and for an expansion nozzle diameter of $300 \mu \mathrm{m}$ (right) (av $\pm \mathrm{Sm} ; \mathrm{n} \geq 3$ ).

To verify this assumption and to enable a comparison of the droplet sizes in the emulsion to those in the aerosol, a disintegration factor is introduced (figure 9). The average values were between 32 and 142. For both emulsification nozzles, the disintegration factor decreases with increasing water mass load, confirming the evaporating $\mathrm{CO}_{2}$ as the driving force of the droplet breakup. 


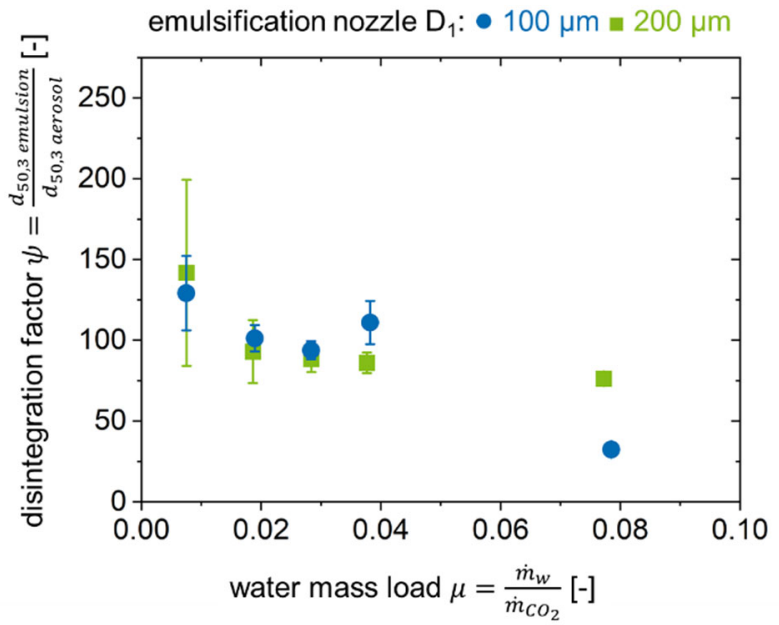

Figure 9. Calculated disintegration factor in dependence of the water mass load for an expansion nozzle of $200 \mu \mathrm{m}(\mathrm{av} \pm \mathrm{Sm} ; \mathrm{n} \geq 3)$.

\section{Conclusions and Outlook}

The presented results show a new approach for producing droplets with a median diameter smaller than $10 \mu \mathrm{m}$. Droplet sizes between 240 and $730 \mu \mathrm{m}$ were measured in the emulsion. Although the highest mode of disintegration, the atomization regime, was reached, no significant decrease in droplet size was observed. As the droplet size in the emulsion seems to present the highest potential of optimization, it will be the focus of future research. It shall be investigated if a significant decrease in droplet size in the emulsion can be reached by increasing the Reynolds number. As the current photographic method to measure the droplet size in the emulsion is limited, the laser diffraction technique shall also be used for the emulsion with a newly designed high-pressure cuvette.

\section{Nomenclature}

$\mathrm{d}_{50,3} \quad$ volumetric median droplet diameter [ $\left.\mu \mathrm{m}\right]$

D nozzle diameter [ $\mu \mathrm{m}]$

$D_{1} \quad$ diameter of the emulsification nozzle $[\mu \mathrm{m}]$

$\mathrm{D}_{2} \quad$ diameter of the expansion nozzle $[\mu \mathrm{m}]$

$\mathrm{L} \quad$ length $[\mu \mathrm{m}]$

$\dot{m}_{\mathrm{CO}_{2}} \quad$ mass flow rate of $\mathrm{CO}_{2}\left[\mathrm{ml} \mathrm{min} \mathrm{min}^{-1}\right]$

$\dot{m}_{W} \quad$ mass flow rate of water $\left[\mathrm{ml} \mathrm{min}^{-1}\right]$

Oh Ohnesorge number [-]

$s_{m} \quad$ mean error of the mean value

$\mathrm{Re} \quad$ Reynolds number [-]

$\eta_{1} \quad$ dynamic viscosity of a liquid phase [Pa s]

$\eta_{w} \quad$ dynamic viscosity of water [Pa s]

$\rho_{1} \quad$ density of a liquid phase $\left[\mathrm{kg} \mathrm{m}^{-3}\right]$

$\rho_{w} \quad$ density of water $\left[\mathrm{kg} \mathrm{m}^{-3}\right]$

$\sigma \quad$ surface tension/ interfacial tension $\left[\mathrm{N} \mathrm{m}^{-1}\right]$

$\mu \quad$ mass load of water [-] 


\section{References}

[1] Jiang D., Xie J., Chen M., Di Li, Zhu J., and Qin H., 2011,"Facile route to silver submicron-sized particles and their catalytic activity towards 4-nitrophenol reduction," Journal of Alloys and Compounds, 509(5), pp. 19751979.

[2] Al-Kassas R., Bansal M., and Shaw J., 2017,"Nanosizing techniques for improving bioavailability of drugs," Journal of controlled release, 260, pp. 202-212.

[3] Czerwonatis N., and Eggers R., 2001,"Disintegration of Liquid Jets and Drop Drag Coefficients in Pressurized Nitrogen and Carbon Dioxide," Chem. Eng. Technol., 24(6), pp. 619-624.

[4] Riestenberg D., Chiu E., Gborigi M., Liang L., West O. R., and Tsouris C., 2004,"Investigation of jet breakup and droplet size distribution of liquid $\mathrm{CO} 2$ and water systems-implications for CO 2 hydrate formation for ocean carbon sequestration," American Mineralogist, 89(8-9), pp. 1240-1246.

[5] Ernst J., 2015. Experimentelle und numerische Analyse des Impulses von aufbereitetem Kraftstoffspray im düsennahen Bereich der Dieseleinspritzung, Springer Fachmedien Wiesbaden, Wiesbaden.

[6] Kemmere M. F., 2005. Supercritical carbon dioxide: In polymer reaction engineering, Wiley-VCH, Weinheim.

[7] Schneider C. A., Rasband W. S., and Eliceiri K. W., 2012,"NIH Image to ImageJ: 25 years of image analysis," Nature methods, 9(7), pp. 671-675.

[8] Mescher A., and Walzel P., 2010,"Störeinfluss durch Schlieren bei der Tropfengrößenmessung an Zweistoffdüsen durch Laserbeugungsspektrometrie," Chemie Ingenieur Technik, 82(5), pp. 717-722.

[9] Teng H., Kinoshita C. M., and Masutani S. M., 1995,"Prediction of droplet size from the breakup of cylindrical liquid jets," International Journal of Multiphase Flow, 21(1), pp. 129-136. 